\title{
Origens do futebol de Muriaé/MG: da novidade foot-ball aos primeiros clubes criados $(1906-1920)$
}

\author{
The Origins of the Football in Muriaé City: From New Foot-Ball \\ to Early Created Teams (1906-1920)
}

\author{
Helcio Ribeiro Campos \\ Inst. Fed. do Sudeste de Minas Gerais, Barbacena/Brasil \\ Doutor em Geografia Humana, USP \\ E-mail: helcio.campos@ifsudestemg.edu.br
}

\begin{abstract}
Resumo: 0 texto versa sobre as origens do futebol de Muriaé/MG, abrangendo o envolvimento da sociedade local com a então novidade foot-ball. Aborda ainda como e quando o futebol se tornou conhecido localmente até a criação dos clubes pioneiros e seus primeiros jogos, desde 1906. Para tal, foram traçados os amplos contextos sociais que influenciaram a chegada do futebol a Muriaé, casos do país e da Zona da Mata, mesorregião de Minas Gerais onde a cidade está localizada. A consecução do estudo veio a partir da observação e pesquisa in loco e por diferentes fontes de coleta de dados, jornais, arquivos públicos, pesquisas sobre clubismo etc. Foi empreendida uma reconstrução histórica da chegada do futebol a Muriaé, focando na adesão social e em suas repercussões, valendo-se de jornais locais disponibilizados nos arquivos da Gazeta de Muriaé e no Arquivo Municipal de Muriaé, valiosas fontes de informações primárias.
\end{abstract}

Palavras-chave: Primórdios do futebol de Muriaé/MG; Primeiros clubes; Modernidade; Primeiros jogos.

ABSTRACT: This text is about the origins of Muriaé/MG city football, covering the involvement of the local society with the early football novelty. He also discusses how and when football became known locally until the creation of pioneer football clubs and their first games, since 1906. To do this, we drew a broad social context that influenced the arrival of football in Muriaé city and some cases in the country and Zona da Mata, a mesoregion of Minas Gerais state, where the city is located. The study was based on observation and research in loco and by different sources, newspapers, public archives, research on clubs. A historical reconstruction of the arrival of football in Muriaé was undertaken, focusing on the social adhesion and its repercussions, using local newspapers made avaiable of the Gazeta de Muriaé and the Arquivo Municipal de Muriaé, valuable sources of primary information.

KEYwords: Football's Beginnings in Muriaé; First Football Clubs; Modernity; First Games. 


\section{INTRODUÇÃO}

Este texto versa sobre as origens do futebol de Muriaé, cidade da Zona da Mata, sudeste de Minas Gerais, abrangendo a participação e o envolvimento da sociedade local com a então novidade foot-ball, que chegava e se consolidava junto com as modernidades (nacional, regional matense e local, muriaeense) por meio da ferrovia que cruzava a cidade, de seus imigrantes, impressos etc., em pleno período cafeeiro. 0 artigo aborda ainda como e quando o futebol se tornou conhecido localmente até a criação dos clubes de futebol pioneiros (extintos) e da confirmação de seus primeiros jogos (intermunicipais, inclusive).

A consecução do estudo veio a partir da observação e pesquisa in loco, de cinco anos já vividos na cidade e por diferentes fontes de coleta de dados (jornais, arquivos públicos, pesquisas sobre clubismo etc.). Foi empreendida uma reconstrução histórica da chegada do futebol a Muriaé, focando na adesão social e em suas repercussões, valendo-se de jornais locais (com edições desde o início do século $\mathrm{XX}$ ) disponibilizados nos arquivos da Gazeta de Muriaé e no Arquivo Municipal de Muriaé (AMM), valiosas fontes de informações primárias.

O futebol muriaeense conta com incipiente produção acadêmica, marcada pela escassez (raros textos específicos) e por longos hiatos entre uma obra e outra. Sendo assim, com este estudo buscou-se lançar luz aos processos fundantes do futebol em uma dessas cidades "esquecidas" pela Academia, Muriaé.

\section{MURIAÉ E SEU FUTEBOL}

Embora o foco deste estudo seja o nascimento do futebol em Muriaé, vejamos como tal esporte se desenvolveu na cidade até os nossos dias, servindo, dessa forma, como um meio de percepção de sua sedimentação na sociedade local, algo que deriva de suas origens e que do passado não pode prescindir. 
Com localização na Zona da Mata Mineira, Muriaé, com 110 mil moradores, é o polo de sua microrregião geográfica, composta por mais 19 municípios, ${ }^{1}$ totalizando cerca de 300 mil habitantes (IBGE, 2015).2 A economia local vive do café e revive os tempos da indústria têxtil, por meio das malharias que se distribuem no município.

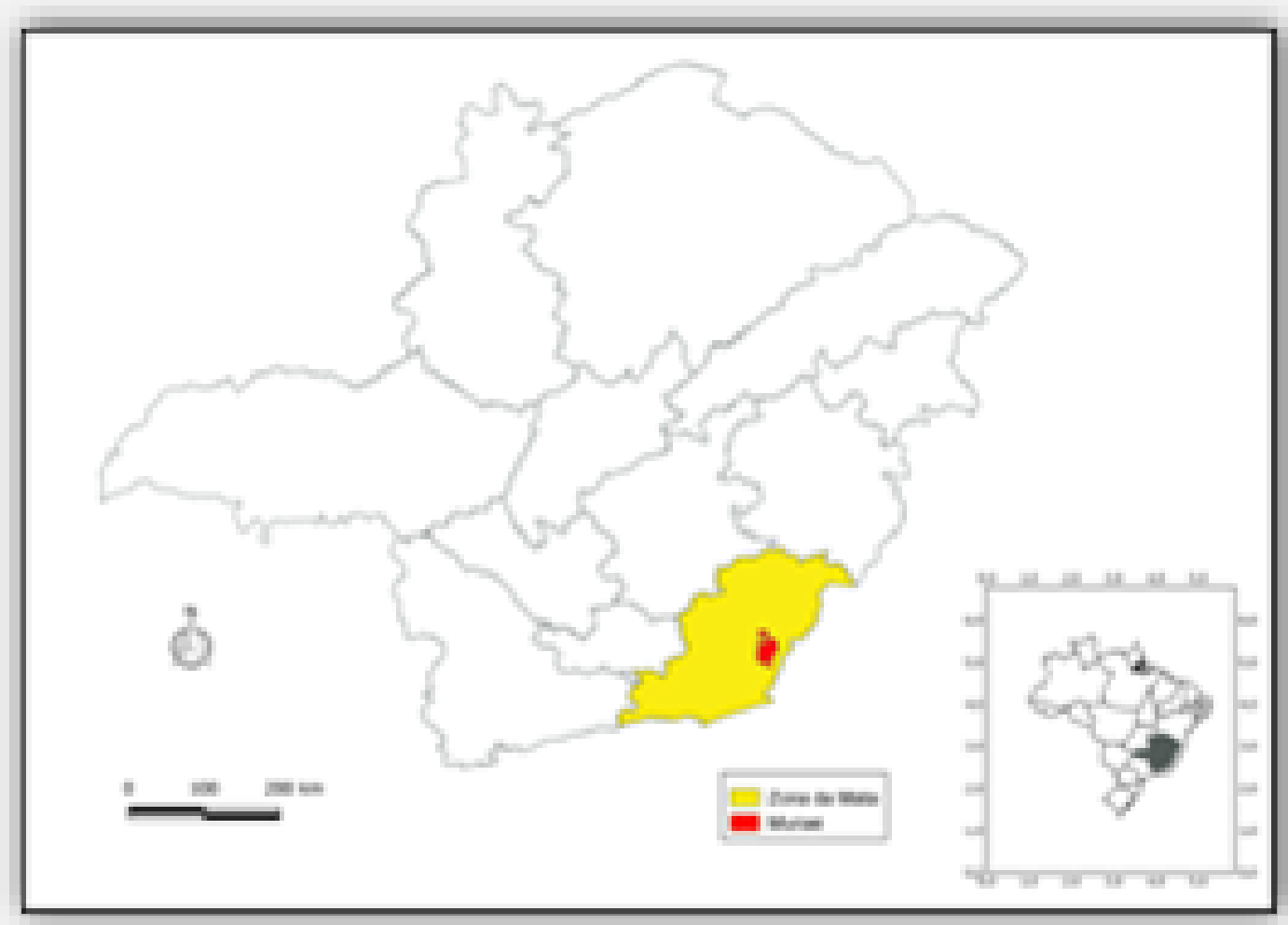

Mapa 1 - Localização de Muriaé em Minas Gerais e na Zona da Mata.

Fonte: o autor, 2018.

0 primeiro registro da prática de futebol em Muriaé data de 1906, jogado no Largo da Matriz, um espaço ainda improvisado no atual Centro da cidade. Contudo, nos bairros é que o futebol local foi instituído na forma clubística: na Armação e na Barra surgiram Athletico Napoleão, Barrense e Paulistano. À exceção do Paulistano, fundado em junho de 1920, as primeiras agremiações locais não perduraram. Em 27 de dezembro de 1927 foi fundado o Nacional, a partir de uma dissidência interna no Paulistano.

\footnotetext{
${ }^{1}$ Divisão do Brasil em Mesorregiões e Microrregiões Geográficas, p. 8. "Conjunto de Municípios contíguos e contidos da mesma UF [sic; Unidade da Federação] definidos com base em características do quadro natural, da organização e de sua integração".

${ }^{2}$ IBGE. Cidades, sem página.
} 


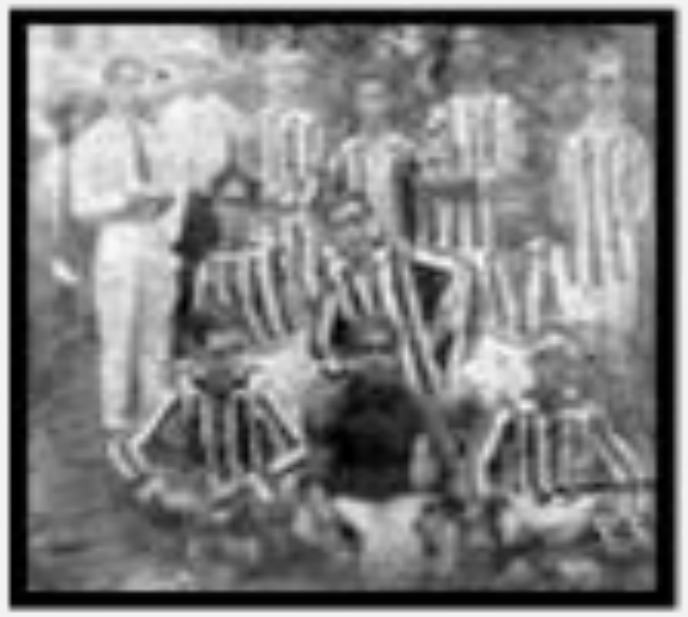

Fonte: AMM, 2017.

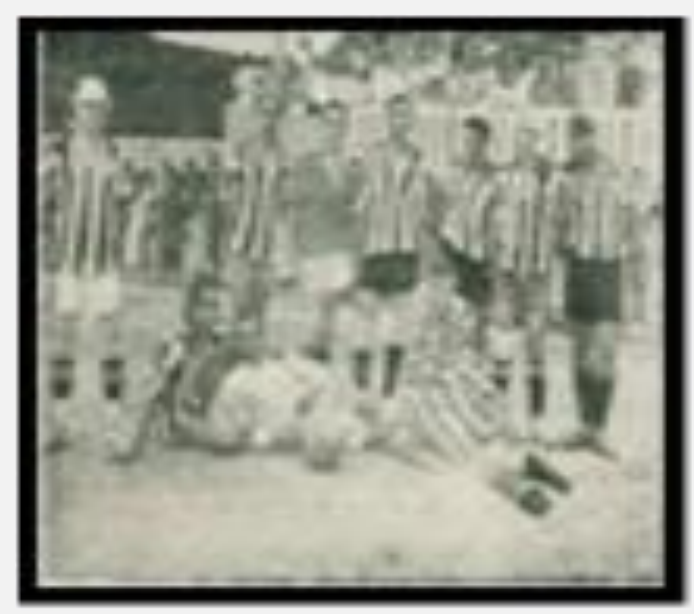

Fonte: Gusman, 1979, p. 102.

Fotos 1 e 2 - Paulistano em 1923 (durante treino) e Nacional em 1930 (em dia de jogo contra o Americano, de Campos/RJ): alguns jogadores em comum.

O auge do futebol muriaeense se deu na década de 1970, e pode ser creditado aos seguidos anos nos quais o Nacional Atlético Clube (NAC), o Nacional de Muriaé, como é chamado, disputou a primeira divisão do Campeonato Mineiro. Porém, a rivalidade com o Paulistano deixou marcas fortes nos torcedores, principalmente entre as décadas de 1930 e 70.

Vários outros clubes amadores, além do Paulistano, o de maior projeção, foram fundados em Muriaé, os quais avolumam as disputas e as rivalidades locais, a exemplo de Operário (8 fevereiro de 1944), Santa Rita (23 maio de 1945), São Cristóvão (21 abril de 1953), Cruzeiro (15 junho de 1953) e Porto (10 outubro de 1964). ${ }^{3}$ Tais associações esportivas representam suas comunidades e bairros, os quais são homenageados nas denominações clubísticas. São exemplos claros de identidade de seus participantes com seus territórios.

A partir dos anos 1980, o futebol de Muriaé passou por seu maior abismo: o Paulistano perdeu seu estádio na Barra, em 1986, enquanto o Nacional chegou a abandonar o profissionalismo, retomando-o depois. Contudo, os últimos anos sinalizam mudanças, o Paulistano está realocando seu estádio, desde 2017, e o NAC está na segunda divisão do Mineiro com o time principal, e na primeira divisão com a base. 0 novo Estádio Soares de Azevedo, com capacidade bem acima do antigo, é um marco recente na história do clube. São novos tempos para o futebol muriaeense.

\footnotetext{
${ }^{3}$ AMM. História de Muriaé, sem página.
} 


\section{CONTEXTOS E CONDIÇõES PARA O NASCIMENTO dO FUTEBol DE MURIAÉ}

\section{$\mathrm{O}$ futebol e a sociedade brasileira na virada do século XIX para o XX}

O futebol aporta no Brasil no final do século XIX (1894), onde se desenvolve nas cidades, praticado por estudantes, em geral jovens da elite com atividades discentes no exterior, sobretudo na Inglaterra, como Charles Miller. ${ }^{4}$ As empresas inglesas atuantes no Brasil representam outra fonte de introdução do futebol, em conjunto com a chegada dos imigrantes e dos estudantes repatriados.

No contexto internacional, esse período foi de redefinição da Divisão Internacional do Trabalho (DIT) e dos centros hegemônicos do capitalismo, reverberando nas diversas escalas territoriais. No Brasil, houve a utilização cada vez maior das atividades não primárias do mercado interno preexistente. 0 motor da nova racionalidade econômica nacional e mundial assentava-se, portanto, na rede de cidades, na economia urbana, onde coexistiam inovações técnicas e mazelas sociais, tendências culturais padronizadoras e novas práticas desportivas. ${ }^{5}$

Daí, do ocaso do século XIX, para as primeiras décadas do século XX, o Brasil passaria por transformações, algumas das quais com nexos destacados com o futebol: 6

1) Ideias higienistas para as cidades: o Movimento Higienista, importado da Europa, foi responsável pela introdução de marcas nos espaços urbanos, como abertura de amplas avenidas, saneamento básico, parques e espaços públicos. Isso fomentou as práticas corporais e os esportes ao ar livre e em espaços especificamente a eles destinados.

2) Início da urbanização brasileira: as cidades brasileiras ainda eram muito envoltas pela produção agropecuária, mas, à medida em que o contato com imigrantes, ideologias e culturas externas crescia, passava-se a ter que conviver com as inovações mais amiúde. Havia um "espírito de mudança" naqueles tempos,

\footnotetext{
${ }^{4}$ CAMPOS. Polarização urbana, identidade territorial e futebol, p. 129.

${ }^{5}$ CAMPOS. Polarização urbana, identidade territorial e futebol, p. 115.

${ }^{6}$ CAMPOS. Polarização urbana, identidade territorial e futebol, p. 129-132.
} 
bondes, ferrovias, carros, iluminação domiciliar e pública, revoltas regionais e separatismos, ex-escravos nas cidades, movimentos populares e sindicais em formação. A vida pulsava intensamente. Dentre essas novidades, o futebol.

3) A prática do futebol, os lugares dos jogos e quem o praticava: as práticas corporais e os esportes foram designados pela ideologia higienista, nascida no século XVII, na Europa, sob o rótulo do mens sana in corpore sano. Para abandonar o sedentarismo, as cidades passaram a contar com programas que repensavam seu espaço urbano, vindo daí o surgimento de vários espaços públicos nos limiares do século XX em diversas localidades, em uma profusão de intervenções urbanísticas. Nas escolas também se copiava o modelo protagonizado na Inglaterra e demais países "civilizados", onde os esportes passaram a ser exaltados como meio de doutrina e disciplina dos jovens. Tal disciplina foi transposta para o campo trabalhista e várias fábricas criaram equipes de futebol, às vezes com vistas a arrefecer os embates entre patrões, sindicatos e empregados. ${ }^{7}$ Isso aumentou o número de pobres e negros praticantes do futebol, como atestam as fotos anteriores (1 e 2) dos times de Muriaé. Muitos desses empregados eram mão de obra experiente, oriunda da Europa, e já conhecedora dos nascentes esportes modernos, assim como os discentes abastados que por lá estiveram para sua formação acadêmica. Imigrantes, operários e estudantes compõem grupos indissociáveis da popularização do futebol no Brasil.

A introdução do futebol passou pelas mãos das escolas, sobretudo as religiosas, com destaque para as escolas dos jesuítas. Essa tradição já era comum no exterior. "Assim, desde o início de 1880, os colégios de Jesuítas da Itália ofereciam, sob um certo controle, o futebol a seus alunos, esporte já bastante desenvolvido naquele país".8

No contexto da contribuição dos imigrantes e de seus filhos para a introdução do futebol no Brasil, sem dúvida o nome que nos vem é o de Charles Miller, que se tornou o "pai do futebol brasileiro" ao retornar da Inglaterra, em 1894, com equipamentos e regras do futebol. Miller ficou familiarizado com o futebol em sua

\footnotetext{
7 ANTUNES. O futebol nas fábricas.

8 MELO. Futebol, p. 18.
} 
escola, em Southampton, e ainda “[...] defendendo clubes locais. Era, de fato, comum aos jovens estudantes, naquele país, se envolverem com a prática de algum esporte". ${ }^{9}$ Miller era paulistano, do Brás, filho de um inglês que viera ao Brasil trabalhar na São Paulo Railway, onde ele também trabalharia. Também outras nacionalidades marcaram os primórdios do futebol no Brasil, com clubes fundados, por exemplo, pelos italianos, portugueses e alemães.

A popularização do futebol ocorreu relacionada com a criação dos campos de futebol de várzea, já que a rede urbana brasileira está muito assentada na penetração territorial e na consequente criação de cidades ao longo da rede hidrográfica. Fátima Antunes ressalta a multiplicação dos clubes de várzea no primeiro quartel do século $\mathrm{XX}, 10$ até porque os "esportes anteriores (turfe, críquete) exigiam espaços específicos e equipamentos caros". ${ }^{11}$ Sendo mais barato e de fácil improvisação, o futebol ganhou mais cidades e adeptos.

Diferentemente de outros países, porém, o Brasil não tem um determinado ponto específico de surgimento do seu futebol. Isso se deu porque as escolas já tinham práticas futebolísticas antes de 1894 (ano do retorno de Charles Miller), mesmo que prescindindo de certas regras específicas desse esporte. 0 futebol escolar ajudou a pulverizar e a consolidar o futebol em todo o país. Um desses exemplos escolares pioneiros vem de 1893, do Colégio Granbery, de Juiz de Fora, ${ }^{12}$ desde aqueles tempos o mais importante núcleo urbano da Zona da Mata mineira.

\section{0 contexto regional: a Zona da Mata}

A Zona da Mata ficou à margem do processo de ocupação do território mineiro durante a fase mineradora na região central de Minas. Junto com o Estado do Espírito Santo e o Vale do Rio Doce, a Mata era um dos "Sertões do Leste", sob o propósito de proteger as regiões das minas. A despeito da proibitiva ocupação por parte de Portugal, a atual Zona da Mata teve que ser rasgada com caminhos que levassem o

\footnotetext{
9 MELO. Futebol, p. 20.

${ }^{10}$ ANTUNES. O futebol nas fábricas, p. 104.

11 MELO. Futebol, p. 21.

${ }^{12}$ CAMPOS. Polarização urbana, identidade territorial e futebol, p. 120.
} 
ouro extraído no centro de Minas até o litoral fluminense, em Parati e no Rio de Janeiro, compondo o Caminho Velho e o Caminho Novo de escoamento. ${ }^{13}$ O Caminho Novo (1705) serviu à ocupação da atual porção centro-sul Zona da Mata, onde está Muriaé, pois ao redor dele as sesmarias (datas) eram cedidas.

O eixo econômico migrara para o circuito ouro-porto da rede urbana dendrítica comandada pelo Rio de Janeiro, a nova capital, que, com sua recente centralidade instaurada, começava longa trajetória de influência sobre Minas Gerais, especialmente na Zona da Mata.

Com a queda da produção mineral ainda no século XVIII, Portugal foi obrigado a revogar a proibição de ocupar os "sertões". Assim, o século XIX marcou a mudança de uma sociedade mais dinâmica e urbana do período minerador para uma sociedade mais estática e rural, de base cafeeira. A rede urbana mineira e matense tendeu a uma desaceleração quanto ao surgimento de novas cidades.

0 café passa a ser o maior trunfo das economias mineira e matense, além de ter proporcionado fortes inversões de capital no setor industrial e com articulações no sistema financeiro, permitindo o destaque de alguns municípios da região no cenário estadual e até no nacional, sobressaindo Juiz de Fora. Cidades e novos habitantes (e imigrantes) surgiam.

A reunião da importância econômica à importância política foi responsável por ensejar a implantação de infraestruturas na Mata Mineira, que a mudariam enfaticamente na transição do século XIX para o XX. A mais notável delas se daria com a chegada das ferrovias. Muitas cidades matenses passariam a contar com linhas férreas nesse período, que era muito marcado pela falta de integração entre os territórios. Isso significou revolucioná-los com a maior chegada de imigrantes e informações. A precariedade dos serviços de comunicação e de transportes fez dos telégrafos, viajantes, jornais, migrantes, ferrovias, serviços de telefonia e rodovias grandes agentes distribuidores de informações. Por todos eles passavam as novidades, os estrangeirismos e demais símbolos e bens da modernidade então em curso, incluindo o futebol.

${ }^{13}$ CAMPOS. A resolução de fronteiras Minas Gerais-Espírito Santo na Zona do Contestado, p. 1013. 
A interseção entre elementos-chave para o entendimento dos locais onde o futebol se desenvolveu na Mata, ou seja, redes viária, de cidades e de jornais, apontam para a divulgação do futebol realizada por viajantes, jornalistas, estudantes e imigrantes, como em Muriaé.

Externamente à Mata Mineira, a decadência cafeeira nacional a contar dos anos 1930 e a perda da condição de capital federal pelo Rio de Janeiro, em 1960, dariam ainda maior dramaticidade ao processo da estagnação regional matense. As retrações de espaço na economia mineira por parte da Mata Mineira não ficaram só na indústria, mas também se deram no setor primário e de transportes, com contínua desativação de ramais ferroviários, cuja malha de 1920 já era muito próxima da atual, sobretudo a contar dos anos 1970, em função do crescimento das rodovias. ${ }^{14}$

Tendo em conta a anterior dinamização econômica proporcionada pela cafeicultura, que gerou a atração de mão de obra regional, interestadual e mesmo estrangeira, italianos e alemães se fixaram em muitas cidades matenses, bem como o contato dos estudantes das classes mais ricas com o futebol, filhos de fazendeiros, comerciantes e industriais, todos esses agentes lograram êxito em torná-lo conhecido na região. Destarte, é verídico atestar as situações em que tais fatores pesaram no aparecimento e na consolidação do futebol, a exemplo de Muriaé.

\section{ORIGENS: ENFIM, CHEGOU O FUTEBOL A MURIAÉ}

O futebol surgiu em Muriaé do mesmo modo como em diversos pontos dos territórios nacional e matense, ou seja, por intermédio das ferrovias e dos contatos que elas proporcionavam, além da divulgação possibilitada pelos jornais, estudantes e escolas, bem como pelos imigrantes.

Foi assim que chegou à cidade, pela ferrovia, Napoleão Lopes da Silva, de origem norte-fluminense, de Campos dos Goytacazes, que, junto com outros sportsmen, seria responsável pela criação da primeira associação esportiva local, o Athletico Napoleão. 0 nome do clube foi uma forma encontrada pelos precursores do futebol muriaeense para homenagear o empenhado Napoleão. ${ }^{15}$

\footnotetext{
${ }^{14}$ CAMPOS. Polarização urbana, identidade territorial e futebol, p. 168.

15 GUSMAN. O futebol na história de Muriaé, p. 126.
} 
Passemos agora a observar o contexto social que existia nesse período e que permitiu a instalação do futebol na cidade.

\section{A sociedade muriaeense conhecendo o Foot-Ball}

Muriaé teve o ramal da Estrada de Ferro Leopoldina instalado em 1866. ${ }^{16}$ Esta antiguidade das ferrovias na Mata Mineira está relacionada com a expansão cafeeira em Minas Gerais e nos seus estados vizinhos - São Paulo, Rio de Janeiro e Espírito Santo. Esses dois últimos, pela proximidade geográfica com a Zona da Mata, têm muita influência na sociedade urbana matense ainda incipiente no século XIX e às voltas com as novidades da época, caso do então Foot-Ball. Diversos amistosos interestaduais entre equipes desses estados estão registrados nos primórdios do futebol de diversas das suas municipalidades, conforme atesta a tese de Campos. ${ }^{17}$

Além da linha férrea, impressos, como 0 Muriaé, 23 de julho de 1891, o mais antigo, e outros três periódicos surgiram ainda no século XIX, quando o futebol era novidade que chegava pela Leopoldina. Por isso, em 1915 o jornal Alto Muriahé assim se reportou após o primeiro jogo intermunicipal local: "A équipe do Tombense seguiu no dia seguinte [12 de julho de 1915, uma segunda-feira] pelo trem da manhã para Tombos do Carangola [...]". ${ }^{18}$ Deve-se também às escolas um papel capital na divulgação do futebol - Grupo Escolar Silveira Brum, 1912; Atheneu São Paulo, 1913, atual Colégio São Paulo.

Ressalta-se que, se os problemas urbanos fizeram o higienismo ganhar terreno nas principais cidades do país, e o interior, que se encontrava ainda mais assolado, acabou por acatar os preceitos higienistas com motivos até maiores, tendo em conta tamanha gravidade socioeconômica, a despeito das infraestruturas que eram instaladas, tais como saneamento, iluminação pública, telefonia etc.

Por meio desse conjunto crucial de fatores - ferrovias, jornais, imigrantes e escolas -, gradativamente, a sociedade muriaeense ia tomando conhecimento acerca das modernidades que já ocorriam em outras cidades, dentre as quais o futebol.

\footnotetext{
${ }^{16}$ FARIA. O que ficou dos 178 anos da história de Muriaé, p. 52.

${ }^{17}$ CAMPOS. Polarização urbana, identidade territorial e futebol.

${ }^{18}$ ALTO MURIAHÉ. Foot-Ball, p. 1.
} 


\section{0 primeiro bate-bola: Largo da Matriz, 1906}

A cidade de Muriaé dispunha de amplos espaços, embora não específicos, para a prática do futebol que, premido pela facilidade com que pode ser jogado, foi ganhando força fora da elite, entre pobres e operários. A ocupação intra-urbana apresentava amplos interstícios entre as áreas centrais, de maior densidade de construções e de habitantes, com lotes menores e maior dotação de equipamentos/infraestrutura, e as áreas suburbanas, com lotes maiores, empreendimentos industriais, bairros de operário e de classe média. Isso pode ser endossado pelo fato de os primeiros clubes muriaeenses serem oriundos de bairros das cercanias do Centro, como Athletico Napoleão, Nacional (da Armação), Barrense e Paulistano (da Barra).

Além disso, os espaços públicos criados ao redor das igrejas e as praças públicas, oriundos do ideário higienista e planejador, criaram ainda mais espaços e, por conseguinte, maiores condições de se praticar o futebol na cidade como um todo.

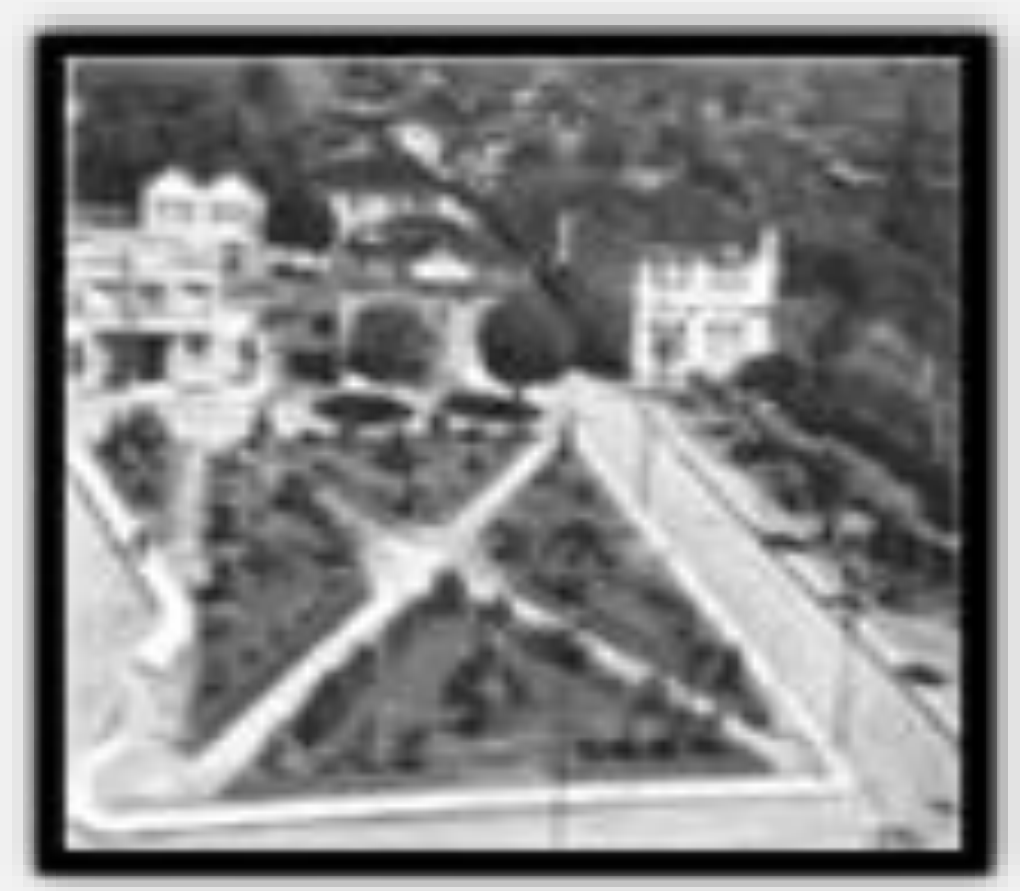

Foto 3 - Visão do Largo da Matriz por volta dos anos 1940. Fonte: Faria, 1995, p. 140. 
O relato mais antigo acerca do futebol de Muriaé vem de 1906, jogado na região central da cidade: "Nessa época apareceu por aqui a primeira bola de couro [...] e os encontros se sucederam no Largo da Matriz, ao tempo uma ampla e lisa área", relata a Gazeta de Muriaé, ${ }^{19}$ em reedição de 1952, que retratou o primeiro jogo intermunicipal, de 1915.

As memórias revelam dois aspectos sobre a origem do futebol muriaeense:

1) Materiais esportivos eram desconhecidos: os materiais próprios do futebol eram praticamente desconhecidos, tendo que ser buscados até fora do país. Portanto, era um feito para a cidade haver uma bola de couro em 1906. Ademais, até os nomes ligados ao futebol, nessa época, eram difíceis para seus praticantes, pois ainda estavam em inglês, já que o futebol moderno nasceu na Inglaterra.

2) Não havia campos de futebol: os espaços específicos para jogar futebol (campos e estádios) ainda não existiam, daí o improviso de se jogar a primeira pelada em plena Praça da Matriz. Todavia, em pouco tempo os espaços, campos, próprios à prática do futebol seriam inaugurados.

Toda essa história de superação das dificuldades iniciais para a implantação do futebol tem nome e sobrenome: Epaminondas Porto, Carlos Andrade, Jacó Campos, Magine, Agripino Veado e Quintino Paiva, dentre outros, são os primeiros futebolistas de Muriaé. ${ }^{20}$

Ressaltemos que os precursores do futebol são, comumente, pessoas das elites. Em Muriaé ocorreu tal situação, incluindo seus divulgadores, a exemplo do então diretor do jornal Alto Muriahé, Antônio Silveira Brum (1874-1942). Seu jornal noticiou o primeiro match interestadual envolvendo o futebol local contra o Tombense, equipe do então vizinho distrito de Tombos do Carangola, terra natal do próprio Silveira Brum, onde começara sua carreira de advogado. Depois, ele foi transferido para Muriaé, onde seria, além de diretor de jornal, promotor, deputado estadual e chefe do Executivo (1905 a 1920), exatamente quando o futebol nascia e se consolidava na cidade, e sob seu apoio. Outra relação, não direta e apenas nominativa, entre Silveira Brum e o futebol, está na criação da primeira escola

\footnotetext{
${ }^{19}$ GAZETA DE MURIAÉ. O futebol em Muriaé, p. 1.

${ }^{20}$ GUSMAN. O futebol na história de Muriaé, p. 125.
} 
pública local, o Grupo Escolar, hoje, Escola Estadual Silveira Brum. ${ }^{21}$ Como as escolas adotaram as práticas corporais e desportivas, pode-se depreender o papel que tiveram na incorporação do futebol no contexto municipal.

A trupe do futebol praticado nas ruas e praças dava trabalho: bola que batia nas casas e suas vidraças; depois, em 1910, houve bolada que comprometeu a fiação elétrica defronte da Matriz, já com a participação de estudantes de Juiz de Fora e do Rio de Janeiro em férias na cidade, ${ }^{22}$ duas cidades que ainda exercem polarização urbana sobre Muriaé. ${ }^{23}$ Ou seja, levaram, e ainda levam, influências culturais, como a do futebol.

Todavia, com o tempo, esses problemas criados ganharam uma solução. Assim nasceram os primeiros campos destinados especificamente ao nascente futebol de Muriaé, bem como suas pioneiras associações futebolísticas.

\section{0 clube pioneiro, seu $1^{0}$ jogo intermunicipal e a linha férrea}

"Aqui aportara um dia, Napoleão, procedente de Campos, montando uma tinturaria e uma agência de jornais, empreendimentos novos em nossa cidade. Espírito associativo, em breve integrado à vida da cidade, topou a idéia da fundação do clube", juntamente com Astolfo Gusman, Artur Werneck, João Pinto de Souza, Orlando Pires (o "Jacu"), Tancredo Ventania e César Janotti. ${ }^{24}$

Tais precursores fundaram o primeiro clube de futebol de Muriaé, chamado de Athletico Napoleão em homenagem ao imigrante empresário de Campos/RJ. Seu ground foi instalado no bairro da Armação, avizinhado com o Centro. "O clube recebeu merecidamente o nome do seu principal fundador", avaliou a Gazeta de Muriaé, em 1952.25

Do mesmo jeito que a linha férrea levou Napoleão de Campos até Muriaé, os futebolistas também se aproveitaram das ferrovias para seus jogos. A primeira partida intermunicipal do futebol de Muriaé envolveu Tombos. 0 jogo ocorreu em

\footnotetext{
${ }^{21}$ AMM. História de Muriaé, sem página.

22 GAZETA DE MURIAÉ. O futebol em Muriaé, p. 6.

${ }^{23}$ CAMPOS. Polarização urbana, identidade territorial e futebol.

${ }^{24}$ GUSMAN. O futebol na história de Muriaé, p. 125.

25 GAZETA DE MURIAÉ. O futebol em Muriaé, p. 6 [jun. 1952].
} 
1915, entre Athletico Napoleão e Tombense, como atesta a primeira página do jornal Alto Muriahé. ${ }^{26}$

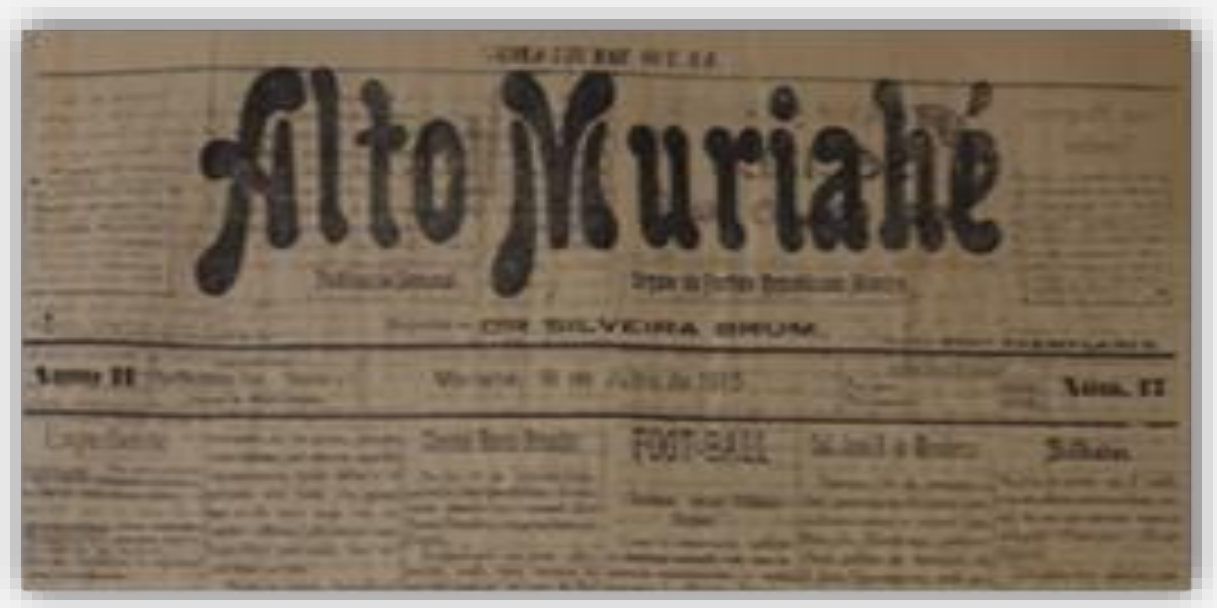

Foto 4 - Detalhe da matéria sobre a primeira partida intermunicipal envolvendo Muriaé. Fonte: Alto Muriahé, 18 jul. 1915, p. 1.

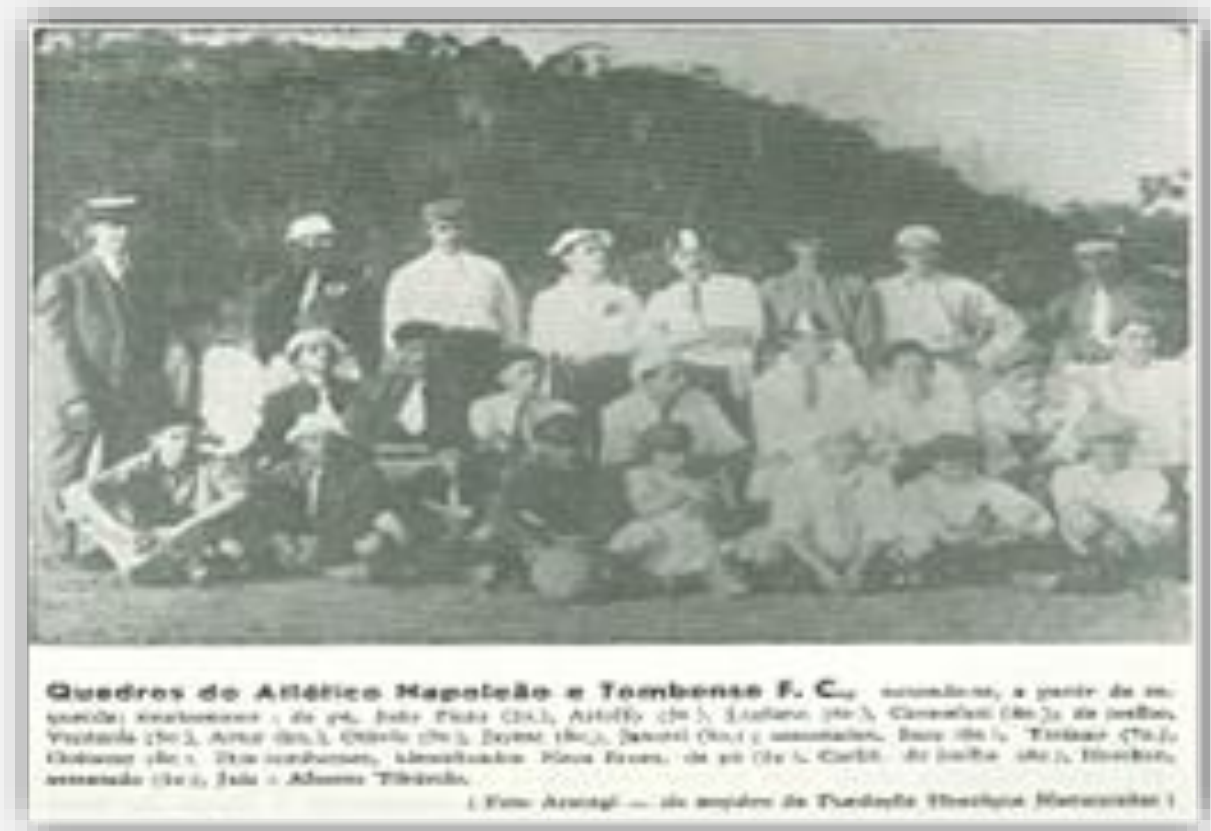

Foto 5 - Athletico Napoleão e Tombense antes do primeiro jogo intermunicipal - 11 jul. 1915. Fonte: AMM, 2017, s/ página.

${ }^{26}$ ALTO MURIAHÉ. Foot-Ball, p. 1. 
A mesma matéria afirma que a partida ocorreu "no último domingo". Como o dia 18 de julho foi num domingo, logo, o primeiro jogo intermunicipal da história do futebol de Muriaé aconteceu no dia 11 de julho de 1915, às $16 \mathrm{~h}$.

0 time muriaeense venceu por 1 tento a 0 , gol marcado por Pires, tornando “[...] nullos os esforços do goal keeper Odillon [...]”, relata o Alto Muriahé.27

IMPACTOS SOCIAIS DA PRIMEIRA PARTIDA INTERMUNICIPAL DE FUTEBOL ENVOLVENDO MURIAÉ

A marcação de um jogo para domingo mostra o poder do futebol como lazer social e mostra ainda como já envolvia a sociedade daqueles tempos, pois contou com grupo de música, homens e mulheres na assistência, como a torcida era chamada, e solenidades.

Contudo, de início, os jogos serviam mais para o entretenimento dos mais ricos, como se depreende das notícias dos jornais de 1915 e reeditados em 1952 pela Gazeta de Muriaé: "Compareceu numerosa assistência, presente ainda o belo sexo [...]", e cita nominalmente as senhoritas da sociedade, “[...] sendo o shoot inaugural dado pela demoiselle Anitta Aguiar". ${ }^{28}$

Quanto ao juiz do jogo, “[...] envergava impecável terno de casemira e chapeu palheta [...]". Como nos teatros europeus do passado, os campos de futebol eram usados pela "boa sociedade" - os ricos - para que fossem observados pelo público presente. Não por acaso, portanto, à “[...] noite, no footing do Jardim, os jogadores eram apontados pelos curiosos". ${ }^{29}$ Segundo o Alto Muriahé, a peleja foi precedida pela apresentação do “[...] afinado Grupo Musical Carlos Gomes, regido pelo competente maestro José Olyntho [...]”.30

Ao mesmo tempo em que o futebol funcionou com alternativa de lazer à medida que amealhou mais praticantes (em uma sociedade que experienciava a decadência socioeconômica cafeeira), também reduziu ou até extinguiu outras formas de lazer e brincadeiras.

\footnotetext{
${ }^{27}$ ALTO MURIAHÉ. Foot-Ball, p. 1.

${ }^{28}$ GAZETA DE MURIAÉ. O futebol em Muriaé, p. 6 [22 jun].

${ }^{29}$ GAZETA DE MURIAÉ. O futebol em Muriaé, p. 1 [jul. 1952].

${ }^{30}$ ALTO MURIAHÉ. Foot-Ball, p. 1.
} 


\section{OS JOGOS CONTINUARAM}

A segunda partida intermunicipal do Athletico Napoleão e, logo, de Muriaé, ocorreu em 1916, na cidade de Leopoldina, também na Zona da Mata, a partir do convite do Ribeiro Junqueira (agremiação criada em 1911), aponta a Gazeta de Muriaé. 31

Diferentemente do amistoso contra o Tombense, esse match não foi tranquilo, consoante o relato do beque Artur, do Athletico Napoleão: “Com o gol de Astolfo, corria o jogo já um tanto nervoso [...] quando o goleiro deles agrediu o Wolnei, daí surgindo o sururu, com o encerramento da partida". E a matéria jornalística comprova ainda quão antigo é o anedotário e os "causos" que enredam o futebol: “Constou aqui que João Pinto jogou armado, o que não é verdade”. 32

\section{Após Tombos, Muriaé faz também o primeiro jogo intermunicipal de Patrocínio}

Muriaé marcou presença no futebol do vizinho município de Patrocínio, onde surgiu em 1919. Dois jogos selaram o encontro entre essas cidades, com uma vitória para cada lado, sempre quando o jogo foi realizado em seus respectivos domínios. A partida em Muriaé aconteceu em um campo que ficava na Barra, logo após o antigo Estádio do Paulistano (Waldemar Alpoim), onde, hoje, é a Praça do Trabalhador.

\section{O ATHLETICo NAPOLEÃo NÃo ACABoU EM 1917 COMO DIZEM FONTES DE MURIAÉ}

Conforme a Gazeta de Muriaé33 e Djalma Gusman,34 o Athletico Napoleão "acabou por volta de 1917". Isso é um equívoco na historiografia esportiva da cidade. Minhas pesquisas encontraram uma notícia, acerca das finanças do Athletico Napoleão, datada de 11 de março de 1920 e publicada em O Operario, ${ }^{35}$ o que comprova sua existência além de 1917. Portanto, a data na qual fontes da cidade afirmam que o clube acabou, como se evidencia, é equivocada.

\footnotetext{
${ }^{31}$ GAZETA DE MURIAÉ. O futebol em Muriaé, p. 1 [jul. 1952].

${ }^{32}$ GUSMAN. O futebol na história de Muriaé, p. 127.

${ }^{33}$ GAZETA DE MURIAÉ. O futebol em Muriaé, p. 6 [jul. 1952].

${ }^{34}$ GUSMAN. O futebol na história de Muriaé, p. 128.

${ }^{35}$ O OPERARIO. Futebol, p. 3.
} 
Desse modo, a informação precisa ser corrigida para "acabou por volta de 1920", ou "acabou logo após 1920", pois não foi possível obter a exata data exata do fim do Athletico Napoleão. De todo modo, é certo que a agremiação encerrou suas atividades logo a seguir, posto que deixa de ser mencionado pelas fontes aqui analisadas.

A mesma notícia pesquisada sobre o Athletico Napoleão mostra também ter havido outra associação esportiva na cidade, o Sport Club, fato ainda obscuro nas pesquisas esportivas sobre Muriaé, e que também não reapareceu nos jornais revisitados.

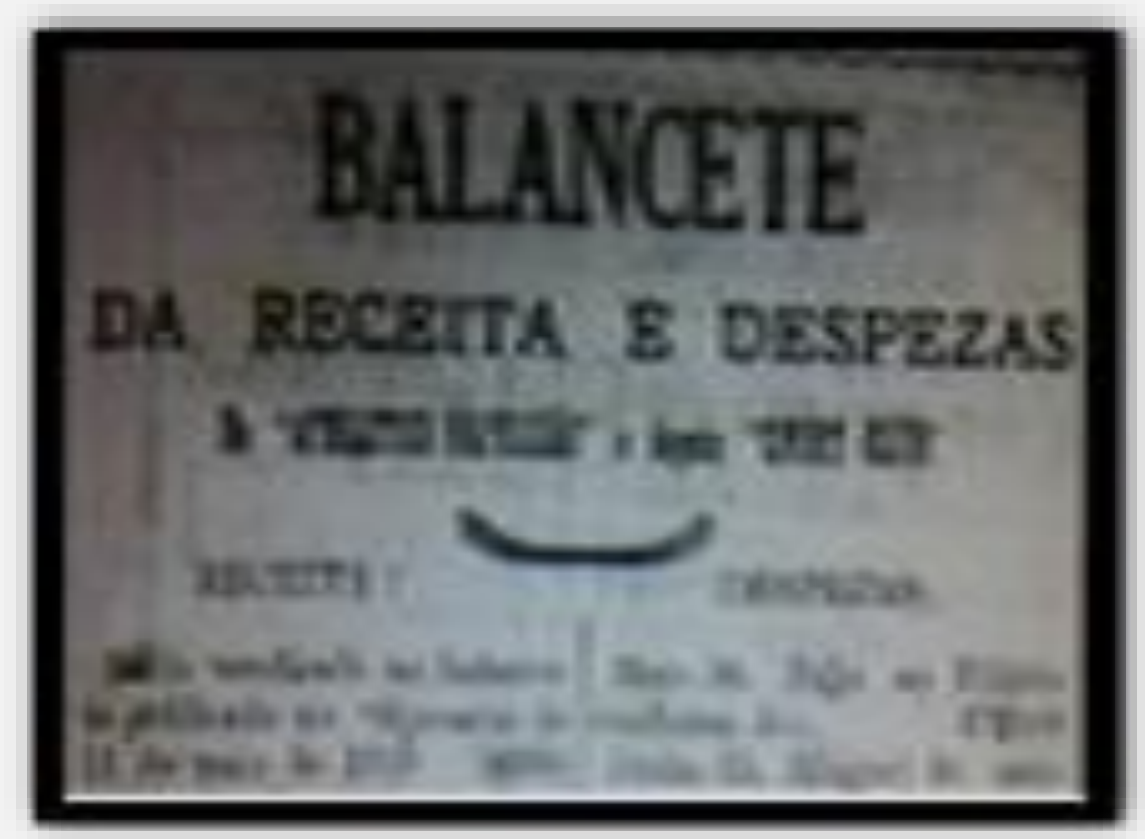

Fotos 6 e 7 - Prova da existência do Athletico Napoleão até 1920 e do Sport Club, obscura agremiação esportiva muriaeense. Fonte: Pereira, 1920; O Operario, 15 mar. 1920, p. 3.

Essa lacuna que o término do Athletico Napoleão deixou foi preenchida fugazmente pelo Barrense Foot-Ball Club, já que essa nova agremiação esportiva também teve vida muito curta. Não há vestígio do ano exato de fundação do Barrense. A denominação clubística estampa uma nova homenagem, desta vez toponímica, em relação ao bairro da Barra.

Apesar do fim de seus primeiros clubes, o futebol local estava vivo na década de 1910, culminando, em 1920, com a criação do Paulistano, que se tornou a primeira agremiação perene de Muriaé (1920), seguido pelo Nacional (1927). 0 percurso dessas associações esportivas marca a sequência do futebol em Muriaé, mas essa já é, literalmente, uma outra história. 


\section{CONSIDERAÇõES FINAIS}

Informações inéditas sobre as origens do futebol de Muriaé foram levantadas a partir deste estudo, quais sejam: a data do primeiro jogo de futebol intermunicipal envolvendo Muriaé, em 11 de julho de 1915; o primeiro time da cidade, o Athletico Napoleão, não "acabou por volta de 1917", como registrava a historiografia local, porque há uma notícia jornalística sobre o clube datada de 1920; houve uma agremiação esportiva chamada Sport Club, fato ainda obscuro nas pesquisas esportivas sobre Muriaé.

De volta aos preceitos gerais que norteiam a adoção do futebol em Muriaé, os agentes clássicos da modernidade, como um todo, estiveram presentes na cidade, a exemplo de imigrantes, estudantes, escolas, utilização de espaços públicos para a prática futebolística, a divulgação por meio da via férrea e dos impressos locais, ambos presentes desde fins de século XIX em Muriaé, e a aceitação social do então foot-ball.

A despeito da simultaneidade do surgimento do futebol de Muriaé com o início do futebol em escalas mais abrangentes, regional e nacional, isso não lhe retira o crédito e o interesse como objeto investigativo. Ao contrário, pois os primórdios do futebol muriaeense apresentam suas especificidades, as quais trouxemos à baila como meio de conhecimento da sociedade local, que não pode prescindir de sua identidade futebolística.

\section{REFERÊNCIAS}

ALTO MURIAHÉ. Foot-Ball. Tombense versus Athletico Napoleão. Alto Muriahé, Muriaé, 18 jul. 1915, p. 1.

ANTUNES, Fátima Martim Rodrigues Ferreira. O futebol nas fábricas. Revista USP, São Paulo, n. 22, p. 102-109, jun./jul./ago. 1994 [Dossiê Futebol].

ARQUIVO MUNICIPAL DE MURIAÉ - AMM. História de Muriaé. Muriaé: FUNDARTE, 2017. 
ASSOCIAÇÃO BRASILEIRA DE NORMAS TÉCNICAS - ABNT. NBR 6023: informação e documentação: referências: elaboração. Rio de Janeiro: 2002, 24 p.

CAMPOS, Helcio Ribeiro. Polarização urbana, identidade territorial e futebol: a Zona da Mata e Juiz de Fora/MG entre o Rio de Janeiro e Belo Horizonte. 2016. 664 f. Tese (Doutorado em Geografia) Faculdade de Filosofia, Letras e Ciências Humanas da USP, Universidade de São Paulo, São Paulo, 2016.

CAMPOS, Helcio Ribeiro. A resolução de fronteiras Minas Gerais-Espírito Santo na Zona do Contestado. Revista Geonorte, v. 7, n. 1, p. 1010-1030, 2013.

FARIA, Maria Auxiliadora de. 0 que ficou dos 178 anos da história de Muriaé. Muriaé: s/ editora, 1995.

GAZETA DE MURIAÉ. O futebol em Muriaé. Memórias de um veterano. Gazeta de Muriaé, Muriaé, 15 jun. 1952, p. 1 e 6.

GAZETA DE MURIAÉ. O futebol em Muriaé. Memórias de um veterano. Gazeta de Muriaé, Muriaé, 22 jun. 1952, p. 1 e 6.

GAZETA DE MURIAÉ. O futebol em Muriaé. Memórias de um veterano. Gazeta de Muriaé, Muriaé, 6 jul. 1952, p. 1 e 6.

GUSMAN, Djalma. O futebol na história de Muriaé. Revista de Historiografia Muriaeense, Muriaé, ano II, n. 2, p. 125-128, mai. 1979.

INSTITUTO BRASILEIRO DE GEOGRAFIA E ESTATÍSTICA - IBGE. Cidades. 2015. Disponível em: <http://www.cidades.ibge.gov.br/>. Acesso em: 01 out. 2017. INSTITUTO BRASILEIRO DE GEOGRAFIA E ESTATÍSTICA - IBGE. Divisão do Brasil em Mesorregiões e Microrregiões Geográficas. Rio de Janeiro: IBGE, 1990.

MELO, Victor Andrade de. Futebol: que história é essa?! In: CARRANO, Paulo Cesar (org.). Futebol: paixão e política. Rio de Janeiro: DP\&A, 2000, p. 12-28.

O OPERARIO. Futebol. O Operario, Muriaé, 18 abr. 1920, p. 3.

PEREIRA, Marius Dornellas. Balancete da receita e despezas do "Athletico Napoleão" e depois "Sport Club”. O Operario, Muriaé, 15 mar. 1920, p. 3. 